\title{
Reducing poverty in the first 18 years of life: monetary and multi-dimensional child poverty in Ethiopia
}

\section{Keetie Roelen, Institute of Development Studies (IDS), UK \\ Research brief}

This research brief presents findings from a mixed methods research project on monetary and multidimensional child poverty in Ethiopia. It uses data from the Ethiopia Rural Household Surveys (ERHS) 1999, 2004, 2009 and purposively collected qualitative data from 61 children and 88 adults in Tigray region to understand patterns and drivers of monetary and multidimensional child poverty. In particular it aims to understand why some children may be multi-dimensionally poor despite living in a household that is not monetary poor and vice versa.

\section{Key messages}

- Monetary and multidimensional child poverty are different phenomena: Children who experience monetary poverty do not necessarily experience multidimensional poverty and vice versa.

- Monetary resources are important for meeting children's basic needs such as food, shelter and clothing. At the same time, household wealth can go at the expense of children's wellbeing in terms of schooling and time use following the importance attached to labour capacity for creating household wealth.

- Evidence for the mismatch between monetary and multidimensional poverty can be found in quantitative and qualitative data, refuting the suggestion that it is purely attributable to measurement error. Mismatch persists over time, and findings do not support the hypothesis that improvements in multidimensional child poverty lag behind improvements in monetary child poverty.

- Psychosocial factors including parents' awareness and attitudes and children's aspirations play an important role in shaping child wellbeing outcomes favourably or in more negative ways regardless of household resources. Factors for shaping attitudes and aspirations include the importance of labour capacity, the availability of role models and wider economic opportunities.

- The availability of public services including schools and health posts play an important role in mitigating the effect of monetary poverty by providing support to secure children's basic needs despite low income or wealth; by the same token, the lack of such services undermines children's wellbeing despite living in a household with sufficient monetary resources.

\section{Monetary and multidimensional child poverty in Ethiopia}

Ethiopia has experienced considerable improvements in its poverty situation in the last three decades. GNI per capita (2005 PPP\$) almost doubled between 1985 and 2011 (UNDP 2011) and national monetary poverty rates are fell from 44\% in 2000 to 30\% in 2011 (WB 2015). Life expectancy increased by 15.3 years from 1980 to 2011 (from 43.9 to 59.3) (UNDP 2011) and infant mortality dropped from 110 to 77 deaths per 1000 live births between 1999/2000 and 2007/2008 (Abebaw 2013). Despite these positive trends, poverty rates differ considerably when using different measures; in 2005, the monetary poverty rate (based on US\$1.25 a day) was 39\% compared to a multidimensional poverty rate (based on Multidimensional Poverty Index) of 89\% (OPHI 2011).

Analysis of monetary and multidimensional child poverty from 1999 to 2009 on the basis of ERHS data shows that poverty trends do not convey an unequivocally positive picture (see Figure 1). Monetary child poverty (based on per capita consumption) increased from $44 \%$ in 2004 to $60 \%$ in 2009, which is in line with general monetary poverty findings for this period from ERHS data and can be largely attributed to inflation (Dercon et al 2012). Multidimensional child poverty (composed of indicators referring to time use, including school attendance and work) increased from 1999 to 2004 but dropped again between 2004 and 2009. Analysis of indicators underlying multidimensional poverty outcomes indicates that the increase from 1999 to 2004 resulted from increased engagement in family work and domestic chores while the decrease from 2004 to 2009 followed improved school attendance rates. 


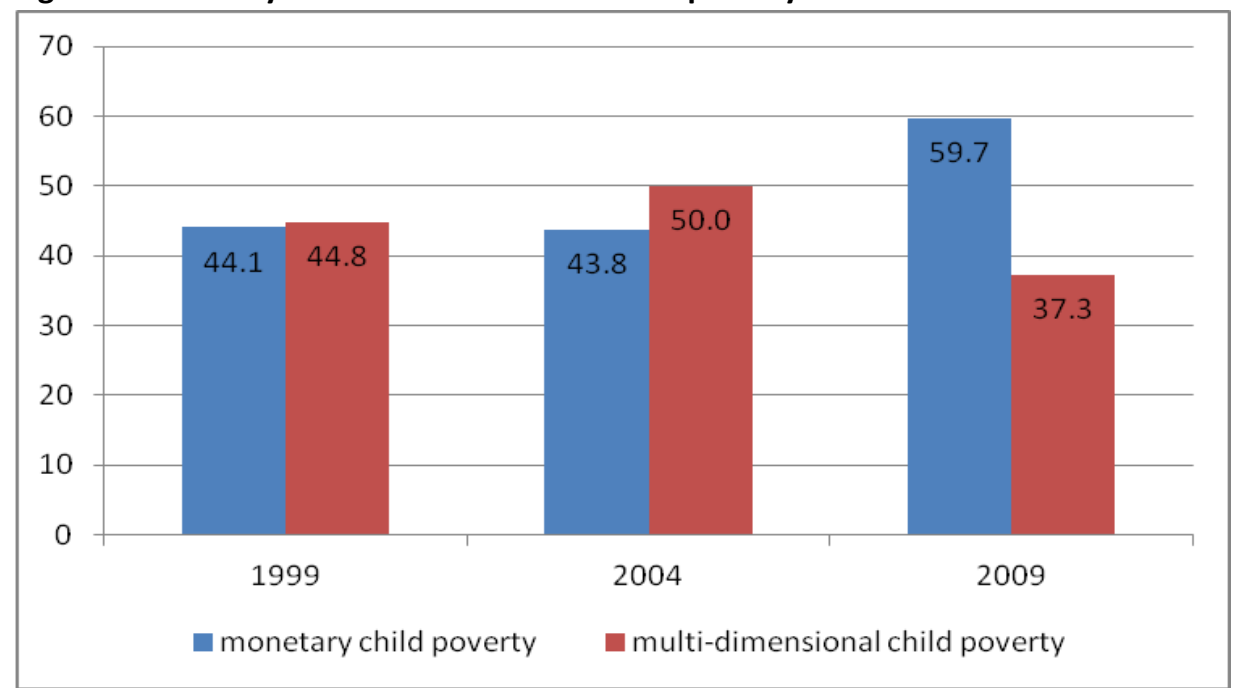

Source: Author's own calculations from ERHS 1999, 2004 and 2009

Although monetary and multidimensional poverty are generally considered to be strongly associated, opposing trends over time suggest that improvements in monetary resources do not always lead to improvements in nonmonetary elements of child poverty. The 2015 WB Poverty Assessment reports that elements of monetary and multidimensional deprivation do not always overlap, and that the degree of overlap has generally decreased from 2000 to 2011 (WB 2015).

This research asked children and adults to describe what constitutes good child wellbeing (or lack of multidimensional child poverty) and household wealth (or lack of monetary poverty). Important elements of multidimensional child poverty include basic and physical needs such as nutrition, clothing, shelter and hygiene, and being able to go to school and using health services when necessary. Components of monetary poverty focus on the capacity to secure basic needs, primarily including labour capacity, livestock and land. Discussions with adults and children reveal that having enough household income is important in securing wellbeing for children, but that it is not a sufficient or sometimes necessary condition. This appears to hold true particularly for the indicators of wellbeing that refer to time use for children, namely school attendance, farm work and domestic chores.

"[Household wealth and child wellbeing] are related and always the same, because rich households usually feed their children well, purchase clothes frequently, send their children to school and provide health care more than the poor families." [child, Harresaw, Harresaw]

"Although poor households have to desire to care for their children, their economic situation does not allow them to do so, while richer households easily fulfil their children's demands because of their financial capacity. [woman, Geblen, Kaslen]

"[Household wealth and child wellbeing are] not related [...] there are many rich families who don't care for their children and on the contrary there are also many poor households who really care their kids. [woman, Harresaw, Harresaw]

\section{Overlap and mismatch patterns}

Analysis of the correlation between per capita consumption and indicators underlying multidimensional child poverty corroborate the mixed relation between monetary and multidimensional child poverty (see Table 1). Not attending school is negatively correlated with monetary resources, i.e. higher household wealth is associated with increased school attendance. The positive sign for indicators 'working on farm' and 'working on domestic chores' however, reflects that a greater level of monetary resources is associated with higher deprivation in these areas. 
Table 1 Correlation between real per capita expenditure and child poverty indicators 1999, 2004 and 2009

\begin{tabular}{|l|c|c|c|}
\hline & 1999 & 2004 & $\mathbf{2 0 0 9}$ \\
\hline & $\mathbf{n = 2 8 9 3 ( 6 - 1 8 )}$ & $\mathbf{n = 2 7 2 6 ( 6 - 1 8 )}$ & \multicolumn{2}{|c|}{ correlation with real per capita consumption } \\
\hline multidimensional poverty status & -0.024 & $0.043^{* *}$ & $0.047^{* * *}$ \\
\hline Indicators & & & \\
\hline not attending school, age 6-18 & $-0.052^{* * *}$ & $-0.043^{* *}$ & $-0.069^{* * *}$ \\
\hline working on farm, age 6-18 & 0.022 & $0.085^{* * *}$ & $0.041^{* *}$ \\
\hline working on domestic chores, age 6-18 & $-0.038^{* *}$ & $0.051^{* * *}$ & $0.059^{* * *}$ \\
\hline
\end{tabular}

Note: Asterisks refer to significance levels of coefficients: ${ }^{*}=p<0.1 ;{ }^{* *} p<0.05 ;{ }^{* * *} p<0.01$

Source: Author's own calculations from ERHS 1999, 2004 and 2009

Further investigation of overlap and mismatch between child poverty outcomes over time indeed suggests that greater monetary resources do not necessarily go hand-in-hand with lower multidimensional child poverty. The Venn diagrams in Figure 2 show percentages of children belonging to different 'poverty groups' constituted by being non-poor, being both monetary and multidimensionally poor, being exclusively multidimensionally poor or being exclusively monetary poor. With roughly half of all children experiencing either exclusive monetary poverty or exclusive multidimensional poverty, across all time periods, it is clear that children living in multidimensional poverty are not necessarily monetary poor and vice versa.

Figure 2 Child poverty groups in 1999, 2004 and 2009

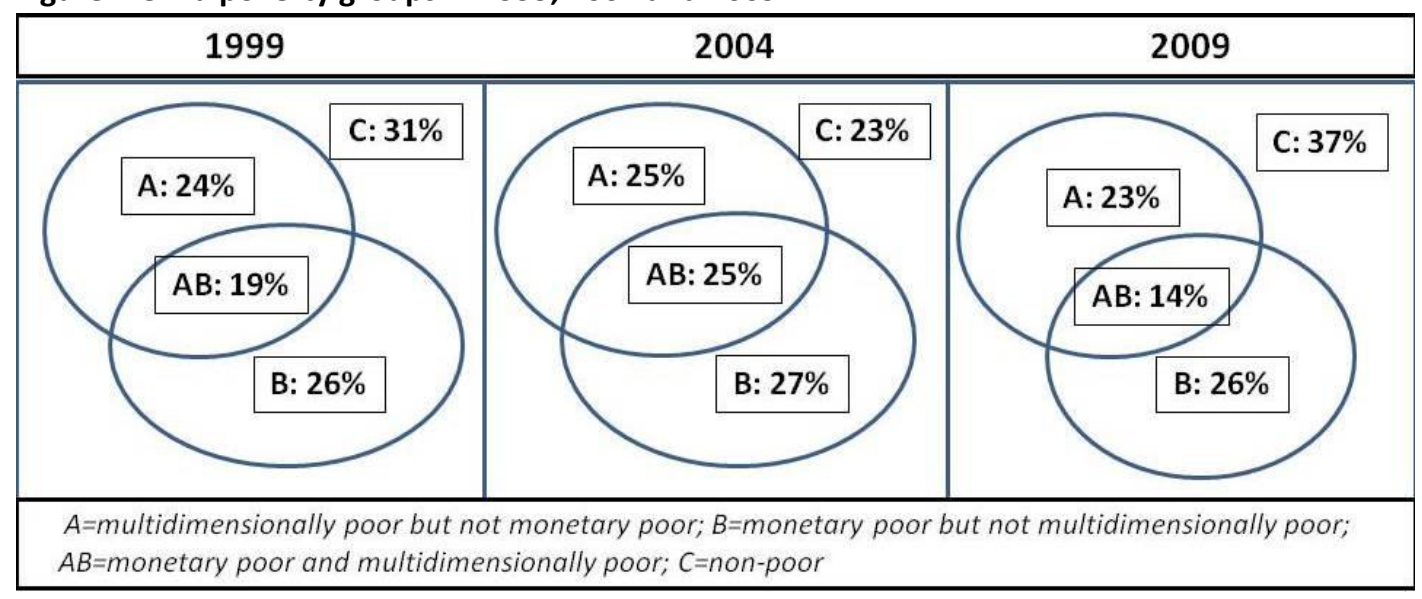

Note: percentages are calculated on basis of monetary poverty line being lowered to obtain the same headcount rate as for multidimensional poverty cancel out size differences

Source: Author's own calculations from ERHS 1999, 2004 and 2009

The mismatch between monetary and multidimensional outcomes of child poverty was also emphasised by both adults and children in the qualitative data. They indicated that although household wealth is important for securing material and physical needs, it does not necessarily secure positive outcomes with respect to schooling or time use.

"Not related, because there are rich households who only care for their wealth and livestock instead of their children." [15-year old girl, Geblen, Kaslen]

Sometimes children in rich households are obliged to work in farm activities rather than going to school. But the children of poor households go to school and the parents have tried to fulfil the necessary educational materials. [woman, Geblen, Kaslen]

\section{Explaining child poverty mismatch}

Expanding research on differential outcomes for monetary and multidimensional (child) poverty suggests that explanations for mismatch between child poverty outcomes can be sought in a number of areas, including (i) measurement error, (ii) improvements in multidimensional poverty lagging behind improvements in monetary poverty and (iii) factors at the community, household and individual level. 
Figure 3 Development of community criteria for household wealth and child wellbeing

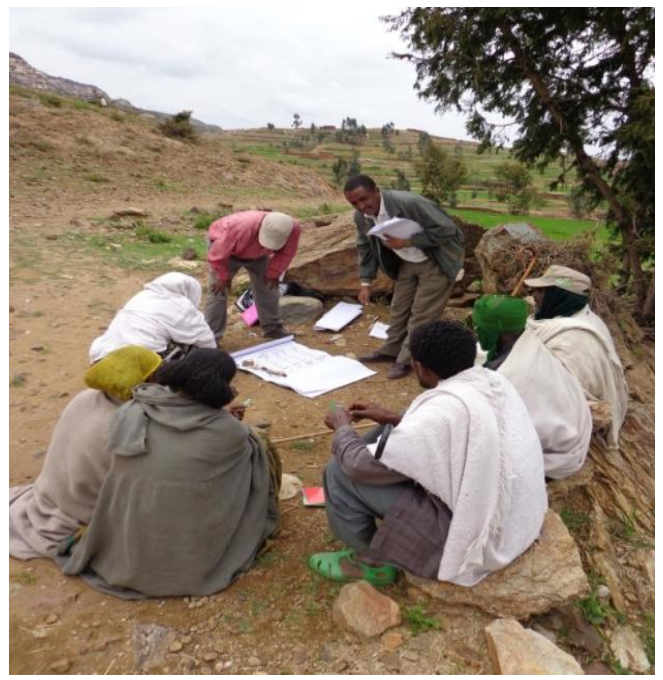

Qualitative findings provide some support for measurement error playing a role in the identification of mismatch between monetary and multidimensional child poverty. As part of qualitative data collection, community members in four sites formulated criteria for household wealth and child wellbeing (see Figure 3 ) and subsequently discussed households' situations with respect to these criteria. Community members indicated household wealth and material child wellbeing to be distinct concepts with their own criteria. However,indicators available in the quantitative data did not directly mirror the criteria as defined by community members, particularly with respect to household wealth (for which availability of livestock, land and labour was mentioned rather than household consumption). Indicators for child wellbeing were more similar with a strong focus on going to school and working at or outside the home. Household consumption serving as an inadequate proxy for community-based criteria of household wealth may result in inadequate identification of monetary poor households, possibly leading to incongruous identification of monetary and multidimensionally poor children. That said, community members in all four sites identified households with inconsistent situation situations regarding monetary poverty and child wellbeing, confirming the existence of poverty mismatch and refuting the suggestion that mismatch is entirely attributable to measurement error.

The existence of lagged effects - i.e. the notion that improvements in multidimensional poverty lag behind improvements in monetary poverty - appears limited. If there were such a lagged effect, large proportions of children would have moved from being simultaneously monetary and multidimensionally poor ( $A B$ ) to being exclusively multidimensionally poor (A) to being non-poor over time (C). Findings in Table 2 do not support this hypothesis: there are many transitions between poverty groups with large proportions changing poverty group from one period to the next. Regression estimates also indicate that poverty group 'membership' in the preceding period is a weak predictor of which poverty group the child belongs to in the next period. This fluid pattern can partly be explained by the indicators underlying the measure of multidimensional child poverty, which refer to time use and are likely to be responsive to short-term changes, as well as the increase in monetary poverty from 2004 to 2009.

Table 2 Transition matrices poverty groups in 1999, 2004 and 2009

\begin{tabular}{|c|c|c|c|c|c|c|c|}
\hline & & & 2004 & & & & \\
\hline & & $N$ & $A B$ & $A$ & $B$ & $C$ & Total \\
\hline \multirow[t]{6}{*}{1999} & $A B$ & 201 & 23.9 & 26.4 & 27.9 & 21.9 & 100 \\
\hline & $A$ & 209 & 19.6 & 37.8 & 11.5 & 31.1 & 100 \\
\hline & $B$ & 272 & 17.7 & 18 & 38.2 & 26.1 & 100 \\
\hline & $C$ & 320 & 14.7 & 26.3 & 20.6 & 38.4 & 100 \\
\hline & & & 2009 & & & & \\
\hline & & $N$ & $A B$ & $A$ & $B$ & $C$ & Total \\
\hline \multirow[t]{4}{*}{2004} & $A B$ & 293 & 33.8 & 13.3 & 39.9 & 13 & 100 \\
\hline & $A$ & 347 & 23.6 & 19.9 & 31.7 & 24.8 & 100 \\
\hline & $B$ & 340 & 19.7 & 10 & 49.7 & 20.6 & 100 \\
\hline & $C$ & 414 & 12.8 & 15.9 & 33.6 & 37.7 & 100 \\
\hline
\end{tabular}

Source: Author's own calculations from ERHS 1999, 2004 and 2009

Rather than pointing towards a lagged effect, findings so point towards a considerable trade-off between household wealth and child wellbeing. In the qualitative fieldwork, adults and children indicated that greater household wealth can go at the expense of child wellbeing when children have to work many hours in the family business or doing domestic chores, sometimes preventing them from going to school. This finding is supported by the positive correlation between household consumption and number of hours spent on family work as reported in Table 1 and further corroborated in Figure 4, which shows that both higher levels of consumption and livestock ownership are associated with more time spent on work within the family. 
Figure 4 Livestock ownership and family work across consumption deciles for children aged 10-15 in rural Ethiopia

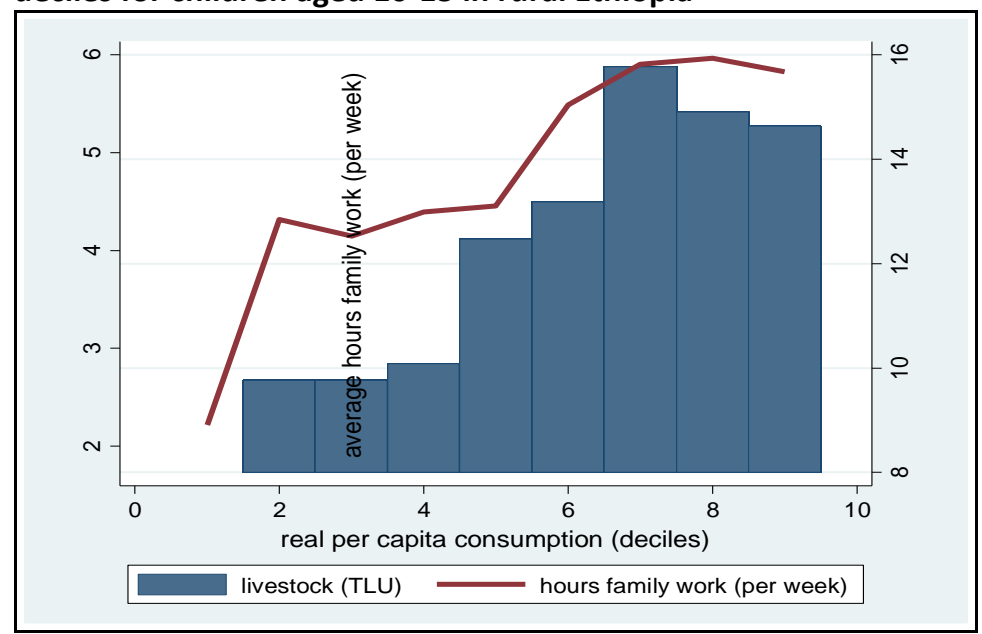

Source: Author's own calculations from ERHS 2009

Notwithstanding the importance of this trade-off, it is important to note however that the relationship between schooling and work is everything but dichotomous (see Tafere and Pankhurst 2015); both children and adults indicated that some level of domestic work was considered to be positive. Indeed, being part of household (re)production can offer socialisation, skills and feelings of self-worth.

Community-level factors are found to play a positive role in improving child wellbeing for all children. School attendance rates in the quantitative sample, for example, rose from 35\% in 1999 to $65 \%$ in 2009 and qualitative findings suggest that the availability of primary education played an important role in this increase. Community infrastructure, particularly in terms of access to schools, health posts and drinking water is important in ensuring children's wellbeing even if children live in monetary poor households. By the same token, the absence of such infrastructure can lead to multidimensional child poverty even if a child is living in a household with greater wealth.

"The wellbeing situation of children in this community has generally improved over time because infrastructure like health posts, and primary education are established near to our community. Nevertheless, there are still some critical problems affecting children like long distance to get to school above grade 4 and lack of potable water." [social worker, Harresaw, Harresaw]

Household-level factors play a large role in explaining differential outcomes of child poverty. Quantitative regression estimates indicate that living in a larger household increases the likelihood to be exclusively monetary or simultaneously poor but decreases the chances of being exclusively multidimensionally poor, possibly because greater household size lessens the need for children to withdraw from school or work many hours. Education of the household head is also important, and this importance intensified from 1999 to 2009. In 2009, living with a household head without any education considerably increased chances of being simultaneously monetary and multidimensionally poor. In 2004 and 2009, living with a household head who had completed primary education or more considerably increased chances of being exclusively multidimensionally poor, suggesting that primary education or more leads to improved economic outcomes for households but does not go hand in hand with greater child wellbeing in terms of school attendance and work in and outside of the house.

Perspectives from adults and children in the qualitative data indicate that awareness and attitudes of parents are crucial in determining good wellbeing for children; they can secure child wellbeing even when the household has few monetary resources but also contribute to poor child wellbeing despite the availability of monetary resources. Qualitative findings point towards a gendered effect, both on behalf of the adults and children. With respect to adults, children experiencing good wellbeing despite living in a poor household were more likely to be part a femaleheaded household, while children experiencing poor wellbeing despite living in a relatively affluent household were more likely to be part of a male-headed household. In cases whereby children were spending many hours working, girls were more likely to undertake domestic chores and boys to work on the family farm and herding livestock. 
Finally, children's aspirations were also considered an important factor in determining whether a child was going to school or not regardless of monetary resources: seeking low-skilled work in Saudi-Arabia was frequently mentioned as a more desirable opportunity than continuing education in pursuit of a skilled job in the local area. Limited economic opportunities and lack of role models appeared to feed into these aspirations. The case study of Sara (Case study I) displays a clear aspiration for attaining skills but also the barrier to fulfilling her ambitions as put up by her father's attitudes to education versus work at home.

\section{Case study I - Sara from Harresaw}

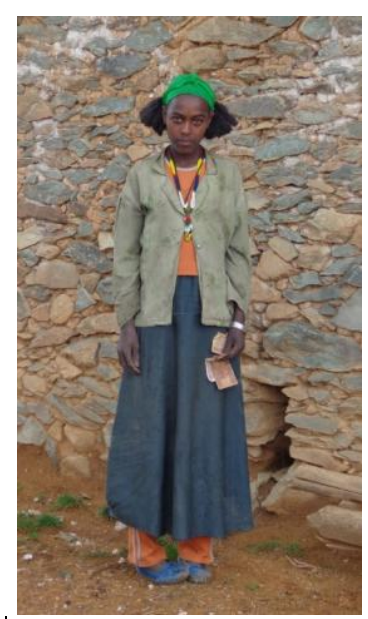

Sara from Harresaw is 16 years old and is currently attending grade 8 . Her family is considered to do fairly well as they own land, have an oxen and cow, sheep and goats and bee colonies. She has mixed feelings about her wellbeing based on the fact that she is going to school but that she needs to do heavy domestic work when at home:

"I can say my wellbeing is good and bad. It is good because I am in school. My wellbeing is bad because I am working at home when I return from school."

Sara's father indicates that he does not send his children to work elsewhere but that he finds it important that they help with work at home:

"I don't send my children to work for other households but I believe children should work at home in household production."

Sara aspires to be an engineer but feels that she is not supported by her father as he wants her to go to a local secondary school rather than in the nearby district town:

"If I pass the national examination, I want to continue my education in the town of Atsbi. But my father wants me to join the Dera high school in order to support him. I want to be an engineer in order construct roads to my community in particular and my country in general."

\section{Further reading}

Abebaw, D. (2013) Infant and Child Health in Ethiopia: Reflections on Regional Patterns and Changes. Journal of International Development 25(4), 536-548.

Dercon, S., Hoddinott, J. and Woldehanna, T. (2012) Growth and Chronic Poverty: Evidence from Rural Communities in Ethiopia. Journal of Development Studies 48(2), 238-253.

OPHI (2011) Country Briefing Ethiopia. Multidimensional Poverty Index (MPI) At a Glance. OPHI: Oxford.

MoFED (2012) Ethiopia's Progress Towards Eradicating Poverty: An Interim Report on Poverty Analysis Study (2010/11). Ministry of Finance and Economic Development: Addis Ababa.

Tafere,Y.and Pankhurst, A. (2015) Children Combining Work and School in Ethiopian Communities. OSSREA: Addis Ababa.

UNDP (2011) Human Development Report 2011 Sustainability and Equity: A Better Future for all. Explanatory note on 2011 HDR composite indices. Ethiopia. New York: UNDP.

WB (2015) Ethiopia Poverty Assessment. Addis Ababa: Poverty Global Practice Africa Region, World Bank.

\section{Acknowledgements}

This research brief was written in August 2015. The author would like to acknowledge the invaluable support of Tsegazeab Kidanemariam Beyene, Hayalu Miruts, Francisco Cabrero Hernandez, Helen Karki Chettri and Kimberly Wied in the process of data collection and analysis. This research was funded by ESRC grant ES-K001833-1.

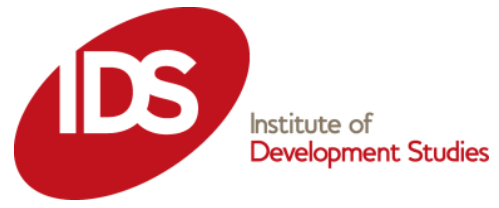

